\section{Therapeutic implications of microRNAs in human cancer}

\author{
Michael Rossbach \\ Genome Institute of Singapore
}

\section{Abstract}

MicroRNAs (miRNAs) are a class of highly evolutionarily conserved non-coding RNAs (ncRNAs) that modulate gene expression. Several studies have shown that the expression of miRNAs is deregulated in human malignancies. For ncRNAs and miRNAs, such gene-profiling studies in tumorigenic tissues have identified significant signatures that are of both diagnostic and prognostic value. Addressing the functions of ncRNAs not only give insights into the molecular mechanisms that underlie complex genetic processes, but may also elucidate novel mechanisms that contribute to early stages of tumor development, progression and metastasis. MiRNA-based novel approaches target the ncRNAome, including, for instance, miRNA expression levels and improved designs of miRNA-mimics or more precise target-predictions, prevent offtarget effects of novel drugs and make miRNAs become a highly efficient class of therapeutics. For miRNA-based therapeutic studies two direct strategies are currently under investigation, viz. (i) the overexpression of given miRNAs to inhibit the expression of proteincoding genes or (ii) the inhibition of target miRNAs with antisense constructs like antagomiRs. Indirect strategies include the use of novel drugs that modulate miRNA expression levels by directly targeting their processing or transcription. Further, miRNAbased biomarkers have a significant impact on the development of both therapeutic and diagnostic agents, a concept known as theranostics and are highly relevant for drug development and personalized medicine.

\section{MicroRNA biogenesis and implications in human cancer}

The biogenesis of microRNAs (miRNAs) is a complex set of sequential steps that begins with the primary miRNA (pri-miRNA) of several kilobases in length, which is transcribed from a miRNA gene by RNA Polymerase II in the nucleus. ${ }^{1}$ Subsequently, the ribonuclease Drosha, which acts in concert with its binding partner DGCR8, ${ }^{2}$ excises one or more stemloop structures of 80 nucleotides in length from this pri-miRNA transcript, resulting in the miRNA precursors, called pre-miRNAs. After being exported from the nucleus to the cytosol in an Exportin-5 mediated reaction premiRNAs are bound and processed by Dicer ${ }^{3,4}$ (Figure 1).

Dicer generates smaller RNA duplexes of 18 25 nucleotides that contain both the mature and complementary miRNA strands. ${ }^{4}$ The complementary strand is degraded, whereas the mature miRNA strand is incorporated in a silencing complex, viz. the RNA-induced silencing complex (RISC). As a result, the mature miRNA targets complementary sequences in the $3^{\prime}$-untranslated region ( 3 ' UTR) of messenger RNAs (mRNAs). Once bound, the mRNA is cleaved or the miRNAs act as translational inhibitors depending on the degree of complementarity ${ }^{5}$ (Figure 1). For a long time, small non-coding RNAs (ncRNAs) were seen as transcriptional noise. However, only $2 \%$ of the human genome encodes protein-coding genes and small non-coding transcripts are involved in the regulation of various cellular processes in normal cells, but can also be dysregulated in disease. ${ }^{6}$ Overall, ncRNAs participate in the regulation of an immense spectrum of processes ${ }^{7}$ and the aberrant expression of ncRNAs has been directly linked to a number of diseases, including several types of tumors. ${ }^{8-11}$ In this regards, ncRNAs, and in particular microRNAs, have been demonstrated to be key regulators of proliferation, evasion, migration and cell death. First evidences came from studies that linked the dysregulation of specific miRNA clusters to leukemia. $^{12}$ The miR-15a/16-1 cluster usually has a direct repressive effect on the anti-apoptotic factor Bcl-2, however, in lymphocytic leukemia (CLL), the miR-15a/16-1 cluster was found to be partially deleted. If the expression level of miR-15a/16-1 cluster is low, the Bcl-2 expression increases, leading to an increased ability to avoid apoptosis, the cells' intrinsic death and tumor suppressor program. ${ }^{13}$ Ever since studies demonstrated the involvement of miRNA clusters in tumorigenesis, miRNAs were shown to act as both tumor suppressors and oncogenes. Aberrant miRNA expression profiles in tumors are frequently associated with chromosomal amplifications and/or deletions $^{11}$ and significant numbers of miRNAs reside in cancer-associated genomic regions and fragile sites or break-points. ${ }^{14}$ Also, significant losses or gains of copy numbers have been shown to be associated with aberrant miRNA expressions. ${ }^{15}$

In cancer development chromosomal regions that encompass miRNAs involved in negatively regulating a transcript from a known tumor suppressor may be amplified. Thus, the amplification of such a region could result in an increased expression of miRNAs and the silencing of a tumor suppressor could
Correspondence: Dr. Michael Rossbach, Genome Institute of Singapore, 60 Biopolis Street, Singapore.

E-mail: rossbachm@gis.a-star.edu.sg

Key words: ncRNAs, microRNAs, oncogenes, tumor suppressor, theranostics.

Acknowledgements: the author thanks K.S Zänker at the University of Witten/Herdecke for helpful discussions and his support. MR's work on ncRNAs was supported by grants of the German National Academic Foundation (Studienstiftung des deutschen Volkes) and the Dr. Meyer-Struckmann Foundation.

Conflict of interest: the authors report no conflicts of interest.

Received for publication: 6 December 2010. Revision received: 28 January 2011.

Accepted for publication: 4 February 2011.

This work is licensed under a Creative Commons Attribution 3.0 License (by-nc 3.0).

(C) Copyright M. Rossbach, 2011

Licensee PAGEPress, Italy

Journal of Nucleic Acids Investigation 2011; 2:e3 doi:10.4081/jnai.2011.e3

be enhanced. Also, miRNAs that inhibit oncogenes under normal conditions could be encoded in fragile chromosomal regions that could be deleted within a cell, leading to a significant decrease in miRNA expression levels. With a lower abundance of repressive miRNAs, oncogene transcripts are increased and may subsequently lead to tumor formation through increased cell proliferation, angiogenesis, invasiveness, migration or metastasis. While miRNAs within tumorigenic cells have an impact on their ability to proliferate or metastasize, miRNAs, and ncRNA in general, are discussed as potentially novel therapeutics. ${ }^{13,16,17}$

As a therapeutic means, one can introduce either miRNA mimics to increase the miRNA levels or anti-miRNAs, so called antagomiRs, to decrease miRNA levels, respectively. In 2007, it was demonstrated that miR-10b is highly expressed in metastatic cancer cells in vitro as well as in metastatic breast tumors from patients. ${ }^{18}$ In 2010, intravenous doses of antagomiRs to miR-10b lead to a decrease in miR10b expression of $65 \%$ and to a corresponding increase of Hox10, the target of miR10b. ${ }^{18,19}$ The transcript of Hox10 is repressed by miR-10b, leading to an increase of RHOC, a pro-metastatic protein. ${ }^{18}$ With the injection of antagomiRs for miR-10b, the ability of breast tumors to metastasize was significantly decreased in mice. ${ }^{18}$ As described, several changes in miRNA expression patterns can be observed in both healthy and diseased contexts; however, for some miRNAs, such 
changes could directly be linked to a tumor suppressor or oncogenic function, respectively. These miRNAs have been termed oncomiRs ${ }^{11}$ and changes in their expression can be used for diagnostic purposes. Also, tumors can be classified according to their origin or differential state..$^{20}$ Beside such diagnostic purposes, miRNA expression signatures give insights into the risk of metastasis or the progression of tumors; ${ }^{21}$ not surprisingly, antagomiRs and miRNA mimics are widely discussed as a means for tumor targeting and therapeutic intervention. ${ }^{17}$

Profiling studies from Volinia et al. ${ }^{15}$ described significant deregulations of miRNAs in tumors of various tissues and origins. Such studies identified several miRNAs and miRNA clusters involved in and specific for tumorigenesis, though correlations with pathology, metastasis and - important in regard to tumor therapy - chemotherapy resistance or treatment outcome were also found. ${ }^{22-24}$ For instance, the miR-17-92 cluster is an example for oncogenic miRNAs, since it is amplified very frequently in several types of cancer, including breast, pancreatic, lung cancer or B cell lymphoma. ${ }^{15,25}$ This cluster targets several genes, among them PTEN and p21. ${ }^{26}$

The cluster of let- 7 miRNAs consists of 13 individual miRNA members and is well known for its tumor suppressive function. In several types of cancer this cluster is repressed and the respective miRNAs are only expressed at very low levels. Let-7 members function through binding to their target oncogenes, among them Ras or c-Myc. ${ }^{27-30}$ Nowadays, cancerous tissue samples are analyzed via beadbased flow cytometric profiling methods. The differences between cancerous and healthy tissue in such global profiles is used to classify human cancers since the observed miRNA expression set reflects the developmental lineage and differentiation status of a cell. However, challenges in identifying a clear profile of miRNAs in malignant tumors remain.

Several studies can indeed link a specific miRNA or miRNA cluster to a particular type and state of cancer, however, some miRNA subsets are shared among the signatures that were identified and sometimes several miRNAs are even opposite expressed among studies. ${ }^{17}$ It seems that the ncRNA and miRNA signatures depend on the profiling platforms, selection criteria and methods used in this particular study. And there is also a high grade of heterogenicity in tumor samples. ${ }^{31}$ Therefore, it is reasonable to be cautious when interpreting miRNA and ncRNA profiles. On the genomic level, when it comes to tumorigenesis, an aberrant oncogene or a malfunctioned tumor suppressor might induce an uncontrolled proliferation or tumor progression. Likewise, on the level of the ncRNAome, the expression of tumor suppressive miRNAs can be downregulated or upregulated in the case of oncogenic miRNAs, respectively. An example for a tumorigenic miRNA by the loss of inhibition of oncogenes is miR-141 that was found to be significantly downregulated in gastric cancer tissues compared to non-tumor tissues. ${ }^{32}$ A low level of miR-141 comes along with a highly proliferative behavior of gastric cancer cells, whereas the overexpression of miR141 in gene transfection studies inhibits the proliferation of gastric cancer cells by inhibiting the expression of FGFR2. ${ }^{33}$ In contrast, the oncogenic miRNA miR-21 has been frequently found to be upregulated in various cancer tissues, including gastric cancer; the overexpression of miR-21 comes along with enhanced invasiveness and cell proliferation. ${ }^{32,33}$ Another example for a miRNA cluster involved in tumorigenesis is miR-106b-25, an oncogenic cluster that is upregulated in several tumor tissues compared to the corresponding normal tissues. This cluster exerts its oncogenic function by suppressing the Cip/Kip family members of cyclin dependent kinase (cdk) inhibitors, viz. p57Kip2, p21Cip1 and p27Kip1. Upon overexpression of the miR-106b-25 cluster, Cdk2 is activated and, subsequently, the G1-S-phase transition in the cell cycle is stimulated.34 When looking at the complex interplay of repressive or activating miRNAs, it becomes evident that a successful tumor therapy requires combinatorial approaches targeting several miRNAs (Table 1).

\section{Mechanistic insights into microRNA deregulation}

Even profiling assays give insights into the network of miRNAs and miRNA clusters involved in human malignancies, the underlying molecular mechanisms are only poorly understood. Deregulations and aberrant expression patterns may be the result of various molecular reactions, be it transcription, processing, chromatin accessibility, epigenetic alterations or alterations in the regulatory systems, e.g. on the ncRNAome level. The basic transcriptional processes of miRNA biogenesis and functions are very similar to the ones of protein-coding genes. Thus, the transcriptional regulation of the ncRNAome might be regulated by transcription factors that also regulate coding genes. In 2008, Petrocca et al. ${ }^{35}$ demonstrated that the transcription factor E2F1 directly controls the transcription of the miR$106 \mathrm{~b}-25$ cluster in gastric cancer cells and that upregulated levels of miR-106b and miR-93 repress the expression of E2F1, respectively, establishing a miRNA directed negative feedback loop.

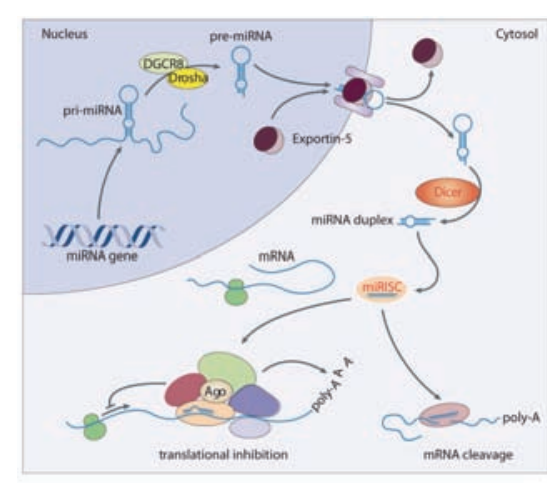

Figure 1. miRNA biogenesis. The transcription of miRNA genes by RNA polymerase II (Pol II) results in primary miRNA transcripts (pri-miRNAs), which are then cleaved in the nucleus by a complex of Drosha and DGCR8. The resulting precursor miRNA hairpin (pre-miRNA) is exported into the cytosol in an Exportin-5 dependent pathway and further processed by the RNase Dicer to an intermediate miRNA duplex. The leading strand is then loaded into the (mi)RNA-induced silencing complex (mi)RISC, whereas the second strand subjected to degradation. The strand selection depends on the thermodynamic characteristics of the miRNA duplex. The (mi)RISC complex is guided to target mRNAs sequences that are located within the 3' untranslated regions (3' UTRs) of the mRNA. Following these reactions, the mRNA is targeted by translational repression and/or degradation.

Many miRNAs and miRNA clusters lie within introns of both coding and non-coding genes and intronic miRNAs are expressed in concert with their host genes. ${ }^{36}$ Thus, alterations in the expression of genes regulating miRNA processing, might also contribute to the deregulation of miRNAs. For instance, in regard to RNA mediated silencing pathways, a loss of Argonaute 2 (Ago2) has been reported to lead to premature stops of the miRNA biogenesis, synthesis and aberrant expression patterns of miRNAs. ${ }^{37}$

Several studies demonstrated that alterations of the epigenetic state, such as histone modifications or hypermethylation reactions have a critical impact on miRNA regulation. ${ }^{38,39}$ Upon treatment with DNA methylation or histone deacetylase inhibitors, like 5-aza-20-deoxycytidine (5-Aza-CdR) or 4-phenylbutyric acid (PBA), respectively, the expression of several miRNAs is upregulated. ${ }^{39}$ In some tissues, the upregulation of specific miRNA clusters that induce the suppression of myeloid cell leukemia-1 (Mcl-1) can be induced by epigenetic treatment, ultimately leading to the apoptosis of tumor cells. Thus, the epigenetic level of regulation in ncRNA and miRNA pathways bears a potential for novel therapeutic approaches in cancer treatment. 


\section{MiRNA-based biomarkers as novel theranostics}

The development of sensitive miRNA-based diagnostic and prognostic markers could significantly improve therapeutic interventions and treatment plans in human malignancies. Assays for early cancer diagnosis, tumor progression, reoccurrence of malignancies or for the evaluation of treatment responses would be very beneficial. MiRNAs bear the advantage of being involved in the regulation of tumorigenesis and are tumor or tissue specific. ${ }^{40}$ Revealing altered miRNA expression patterns could be linked to the status of a tumor, thus using such patterns as predictors for overall survival and as prognostic tools. The predictive values of such miRNA signatures have been validated for several types of tumors. ${ }^{41}$ Further, miRNAs can be used as minimally invasive biomarkers, since miRNA from tumor tissues are stable and present in circulation. ${ }^{42}$ In 2008 , for instance, Chen et al. ${ }^{43}$ identified around 100 miRNAs in human serum and further identified approximately 70 in serum of patients with various types of cancer, viz. colorectal, gastric or lung cancers, compared to samples from healthy individuals. In this par- ticular study, some of the miRNA signatures were unique for a specific type of cancer, i.e. for lung or colorectal cancers, suggesting their potential for differential diagnosis. 43 Also, monitoring the concentration of tumor-specific and -derived miRNAs in patients with malignancies is a means for diagnosis and prognosis. For instance, it has been demonstrated that a set of the four miRNAs miR-17-5p, miR21, miR-106a and miR-106b is upregulated, whereas levels of let-7 are downregulated in gastric cancer patients compared to controls from healthy individuals. ${ }^{44}$ It is of great interest, to link tumor-derived miRNAs in the circulation with stage, differentiation and pathology of a malignant disease, particularly in regard to prognosis, survival, reoccurrence, metastasis or chemotherapy resistance. Such cellular processes are inextricably linked with signal transduction pathways. In 2007, Valadi et al. ${ }^{45}$ demonstrated that miRNAs, packaged in microvesicles, might serve as extracellular signaling entities to mediate intercellular communication.

In 2009 , Kota et al. ${ }^{46,47}$ presented a study on therapeutic miRNA delivery suppressing tumor formation in a murine liver cancer model. The authors demonstrated that hepatocellular carcinoma (HCC) cells exhibit a significantly reduced expression of miR-26a. In liver cancer cells, the expression of miR-26a, a miRNA that is normally expressed at high levels in various tissues, induced cell-cycle arrest associated with the direct targeting of cyclins D2 and E2. Based on the systemic administration of miR$26 \mathrm{a}$ in a mouse model of HCC using adenoassociated virus (AAV) that resulted in an inhibition of cancer cell proliferation, in the induction of tumor-specific apoptosis, and a dramatic protection from disease progression without toxicity ${ }^{47}$ such findings suggest that the delivery of miRNAs can provide a general approach for miRNA replacement therapies. Previously, similar findings were made by Mendell et al., ${ }^{48}$ who demonstrated that MYC-induced liver tumors result in concomitant downregulation of various miRNAs.

MiRNA based biomarkers have a significant impact on the development of both therapeutic and diagnostic agents. With respect to cancer treatment, interest has grown in combining both paradigms to facilitate clinical translations. Thus, this concept, known as theranostics, is highly relevant for biomarker-based drug development and personalized medicine. For the ncRNAome, the link of aberrant miRNA expression with pathogenesis and the progression of malignant diseases paves the way towards

Table 1. MicroRNA-based therapeutic approaches. Characteristics of biological and chemical therapeutic tools using miRNA-based approaches.

\begin{tabular}{|c|c|c|c|c|c|}
\hline Strategy & $\begin{array}{l}\text { miRNA } \\
\text { modulation }\end{array}$ & Advantages & Limitations & $\begin{array}{l}\text { Experimental } \\
\text { data }\end{array}$ & $\begin{array}{l}\text { Clinical } \\
\text { application }\end{array}$ \\
\hline $\begin{array}{l}\text { Inhibition of mature } \\
\text { miRNA by 2'-OME and 2'-MOE } \\
\text { antisense oligoribonucleotides }\end{array}$ & $\begin{array}{l}\text { Modified 2-OH residues of } \\
\text { the ribose 2'-0-methyl/2'- } \\
\text { 0-methoxyethyl }\end{array}$ & $\begin{array}{l}\text { Good bioavailability } \\
\text { and biodistribution, } \\
\text { high stability }\end{array}$ & $\begin{array}{l}\text { Toxicity, off-target } \\
\text { effects, requires } \\
\text { high doses }\end{array}$ & $\begin{array}{l}\text { In vitro and in vivo } \\
\text { data (animals) }\end{array}$ & $\begin{array}{l}\text { Silencing } \\
\text { of oncomirRs }\end{array}$ \\
\hline $\begin{array}{l}\text { Inhibition of pri-miRNA by RNase } \\
\text { H-based antisense } \\
\text { oligoribonucleotides }\end{array}$ & $\begin{array}{l}\text { Short stretch of centrally } \\
\text { located 2' deoxy residues }\end{array}$ & $\begin{array}{l}\text { Good bioavailability, } \\
\text { high stability }\end{array}$ & $\begin{array}{l}\text { Toxicity, off-target } \\
\text { effects }\end{array}$ & In vitro data & $\begin{array}{l}\text { Silencing of } \\
\text { polycistronic miRNA } \\
\text { clusters }\end{array}$ \\
\hline $\begin{array}{l}\text { Inhibition of mature miRNA } \\
\text { by locked nucleic acid (LNA-) } \\
\text { antagomiRs }\end{array}$ & $\begin{array}{l}\text { One or more nucleotide } \\
\text { binding blocks; extra } \\
\text { methylene bridge fixes } \\
\text { ribose moiety }\end{array}$ & $\begin{array}{l}\text { Good biodistribution, } \\
\text { very effective }\end{array}$ & Off-target effects & $\begin{array}{l}\text { In vitro and in vivo data, } \\
\text { clinical trials on-going }\end{array}$ & $\begin{array}{l}\text { Silencing } \\
\text { of oncomirRs }\end{array}$ \\
\hline $\begin{array}{l}\text { Replacement of mature miRNAs } \\
\text { by pre-miRNA-like shRNAs }\end{array}$ & $\begin{array}{l}\text { Natural pre-miRNA to achieve } \\
\text { more persistent miRNA } \\
\text { replacement }\end{array}$ & $\begin{array}{l}\text { Nanotechnology } \\
\text { based conjugations, } \\
\text { very stable, very } \\
\text { effective }\end{array}$ & $\begin{array}{l}\text { Toxicity, off-target } \\
\text { effects }\end{array}$ & In vitro data & $\begin{array}{l}\text { Restoring tumor } \\
\text { suppressor miRNAs }\end{array}$ \\
\hline $\begin{array}{l}\text { Replacement of mature miRNAs } \\
\text { double stranded miRNA } \\
\text { mimetics }\end{array}$ & $\begin{array}{l}\text { Equivalent to endogenous } \\
\text { Dicer products, similar } \\
\text { structure as siRNAs }\end{array}$ & $\begin{array}{l}\text { Nanotechnology based } \\
\text { conjugations, very } \\
\text { stable, very effective }\end{array}$ & $\begin{array}{l}\text { Toxicity, off-target } \\
\text { effects }\end{array}$ & In vitro data & $\begin{array}{l}\text { Restoring tumor by } \\
\text { suppressor miRNAs }\end{array}$ \\
\hline $\begin{array}{l}\text { Silencing of specific targets } \\
\text { with synthetic miRNAs }\end{array}$ & Designed related target mRNA & $\begin{array}{l}\text { Good bioavailability } \\
\text { and biodistribution }\end{array}$ & Limited stability & In vitro data & $\begin{array}{l}\text { Tumor suppressor } \\
\text { functions }\end{array}$ \\
\hline $\begin{array}{l}\text { Inhibition of mature miRNA } \\
\text { with miRNA sponges }\end{array}$ & Sponge plasmid vectors & $\begin{array}{l}\text { Possibility to silence } \\
\text { miRNA families }\end{array}$ & $\begin{array}{l}\text { Limited stability, } \\
\text { poor delivery, } \\
\text { off-target effects }\end{array}$ & In vitro data & $\begin{array}{l}\text { Silencing of clusters } \\
\text { oncomiR-families }\end{array}$ \\
\hline $\begin{array}{l}\text { Polymer-nanoparticle- } \\
\text { oligonucleotide-complexes }\end{array}$ & $\begin{array}{l}\text { 5-Aza-CdR/PBA modifications } \\
\text { conjugates }\end{array}$ & $\begin{array}{l}\text { Enhanced stability } \\
\text { and delivery, minimal } \\
\text { toxicity }\end{array}$ & $\begin{array}{l}\text { Off-target effects, } \\
\text { potential dose data } \\
\text { toxicity effects }\end{array}$ & $\begin{array}{l}\text { In vitro and in vivo } \\
\text { (animals) }\end{array}$ & $\begin{array}{l}\text { Restoring tumor } \\
\text { suppressor miRNAs }\end{array}$ \\
\hline $\begin{array}{l}\text { Adenovirus-associated vectors } \\
\text { coding for miRNAs }\end{array}$ & $\begin{array}{l}\text { Plasmid encoded } \\
\text { miRNAs }\end{array}$ & $\begin{array}{l}\text { Safe and efficient } \\
\text { transduction, } \\
\text { long-term } \\
\text { expression }\end{array}$ & $\begin{array}{l}\text { Off-target effects, } \\
\text { potential dose } \\
\text { toxicity } \\
\text { effects }\end{array}$ & $\begin{array}{l}\text { In vitro and in vivo data, } \\
\text { clinical studies phase I, } \\
\text { II and III on-going }\end{array}$ & $\begin{array}{l}\text { Restoring tumor } \\
\text { suppressor miRNAs }\end{array}$ \\
\hline
\end{tabular}


ncRNAs as targets for therapeutic intervention. For miRNA-based therapeutic studies, two direct strategies are under investigation, viz. (i) the overexpression of given miRNAs to inhibit the expression of protein-coding genes, or (ii) the inhibition of target miRNAs with antisense constructs like antagomiRs. An indirect strategy involves the use of drugs to modulate miRNA expression by targeting their transcription and their processing.

Several types of modifications for antimiRNA antisense oligoribonucleotides (AM0s) are under investigation for their therapeutic potential, among them 2'-0-methyl (2'OMe), 2'-0-methoxyethyl (2'-MOE), 2'-flouro, locked nucleic acids (LNA), cholesterol or phosphorothioate backbone conjugation; such modifications vary in the resulting specificity to target miRNAs but also in their stability to nuclease degradation. ${ }^{1749}$ AMOs have been used to downregulate the expression of overexpressed miRNAs related to cancer development; for instance, a knock-down of miR-21 by AMOs results in a significant reduction of cell proliferation and an increase in apoptosis..$^{50,51}$

It has been demonstrated that the functional restoration of miR-34 by miR-34 mimics impairs malignant cell growth and leads to a cell cycle arrest in the G1 phase. Also, caspase3 is activated, subsequently leading to an increased rate of apoptosis. ${ }^{52}$ MiR-34 functions downstream of $\mathrm{p} 53$, the watchdog of genome integrity and acts as a tumor suppressor by targeting HMGA2, Notch and Bcl-2 genes involved in survival and self-renewal of cancer stem cells. ${ }^{53}$ The concept of cancer stem cells comes along with a major obstacle on the way to successful and effective novel miRNA-based drugs and therapeutics, namely chemotherapy resistance. It has been shown that miRNA-based therapies can be used as a tool to modulate the response of cancer cells to chemotherapy.

In 2008, for instance, Xia et al. ${ }^{54}$ found that miR-15b and miR-16 were downregulated in a multi-drug resistant tumor cell line (SGC7901/NCR) compared with its parental cell line (SGC7901). The enforced expression of miR-15b or miR-16 could sensitize the multi-drug resistant cells and made them susceptible to vincristine-induced apoptosis. Both miRNAs targeted BCL2, thus modulating the apoptotic pathways in the target cells.

Despite such studies, the overall therapeutic potential of ncRNAs, and miRNAs in particular, remains largely unexplored, not to mention the molecular mechanisms behind such therapeutic approaches. Among the obstacles of the application of miRNA-based treatments are potential off-target and side effects, since as described - several miRNAs are expressed in clusters or families and levels of redundancy exist. Also, long-term safety assessments in humans need to be carried out and the expression of a particular target gene might be regu- lated by several miRNAs and other ncRNAs that may compromise the effects of miRNAbased treatments. At present, there is also still a lack of miRNA delivery systems with a sufficient specificity and efficacy. To target the delivery problems, non-viral and viral strategies have been developed. ${ }^{55}$ Among the nonviral strategies are oligonucleotides with chemical modifications, polymers, nanoparticles, hydrogels or liposomes. ${ }^{55-60}$ For oligonucleotide modifications, the state of the art method is the replacement of each non-bridging oxygen in the backbone with a sulphur atom, thus forming a phosphorothioate linkage.$^{55,56}$ The advantage of this modification is the greatly improved in vivo half-life compared to non-modified oligonucleotides. ${ }^{55,56}$ Even tumor regression could be demonstrated in several studies, some drawbacks exist. For instance, and overall, major improvements in tumor therapy were not always observed. ${ }^{55,56}$

An advantage of biodegradable polymers is their capability to protect RNA from degradation and to facilitate the sustained delivery to the target tissues. ${ }^{57,60}$ The same is true for liposomes, built of a phospholipid bilayer with an enclosed aqueous compartment, that interact with oligonucleotides via electrostatic interactions. ${ }^{57}$ If liposomes exhibit a positive charge, they can protect oligonucleotides from degradation by nucleases and thus increase their circulating half time and cellular uptake..$^{56,57}$ Besides polymers and liposomes, hydrogels, microspheres or nanoparticle-miRNA oligonucleotide complexes have also been developed as gene delivery vehicles. Further, target-specific delivery could be achieved via a direct injection of synthetic oligonucleotides into solid tumors.

\section{Future Perspectives}

The field of ncRNAs and their involvement in tumor development is rapidly evolving. Not only is the number of identified tumor specific ncRNAs and their targets increasing, but also the signaling pathways and epigenetic functions are more and more elucidated. In this complex network, miRNAs play an important role in the regulation of gene activity, by switching gene expression on or off, or by finetuning genes that control the cell cycle, viability, cell proliferation, migration or apoptosis, respectively. It was predicted that more than half of the human genes might be regulated by small ncRNAs and the deregulation of ncRNA expression if quite often linked to cancer. Thus, studies addressing the functions of ncRNAs give insight into the molecular mechanisms underlying complex genetic processes, not only in healthy, but also in diseased condi- tions and may elucidate novel mechanisms that contribute to tumor development, progression and metastasis.

It is of high importance to uncover the pathways specific ncRNAs are involved in, especially in regard to tumor specific miRNAs that act as either tumor suppressors or oncogenes, respectively. A detailed mechanistic understanding of the RNA mediated signaling pathways in human malignancies will contribute significantly to the understanding of the molecular mechanisms, which underlie the early stages of tumor development, progression and metastasis. Such understanding will directly lead towards novel therapeutic approaches and will also become a great benefit in terms of diagnostics and for personalized medicine.

In the future, the activation of miRNAs with agomiRs or the silencing with antagomiRs could probably become such a therapeutic tool and novel strategy for cancer treatment. The RNAi technology in general, and the targeted control of gene transcription in particular, has a significant therapeutic potential for novel biomarker-based assays in diagnostics and for the development of novel drugs, also in regard to the emerging field of personalized medicine.

For ncRNAs, gene-profiling studies in tumorigenic tissues have identified significant signatures that are of both diagnostic and prognostic value. Notwithstanding the encouraging results of studies on ncRNAs in this regard, many challenges remain. For instance, the expression of miRNAs in tissues is temporal, spatial specific and is influenced by various factors, including epigenetic signals, pathology, infections etc. Thus, it becomes difficult to identify a consistent ncRNA or miRNA signature for diagnostic and prognostic purposes.

However, generally speaking, small ncRNAs have greatly changed our view of tumorigenesis and comprise a great potential to improve the treatment of malignancies with prospective novel approaches.

For the miRNA field, as it continues to evolve, studies addressing the biogenesis or mechanistic functions in healthy conditions or in malignancies, affect the development of novel therapeutics based on miRNAs. At present, such novel therapeutics are based on the miRNA-mRNA 3'UTR interactions, however, this view may be too simplistic since several complex miRNA mechanisms and regulatory layers on both the protein and the genomic level control gene regulation, leading back to the question "What's regulated in gene regulation?" ${ }^{17}$ With improved designs of miRNA mimics, more precise target-predictions, the prevention of off-target effects, pharmacodynamic and pharmacokinetic studies, distinctive miRNA theranostics will be obtained and at some point, the reprogramming of the ncRNAome or miRNAome of patients with can- 
cer might be possible. Also, in tumor therapy, combined approaches of chemotherapy and novel miRNA-based agents will be possible. An encouraging example is a study in which miR128 has been shown to modulate steroid refractoriness in acute lymphocytic leukaemia. Thus, a strategy to overcome this problem in the treatment of lymphocytic leukaemia is the use of synthetic miRNAs in combination with chemotherapy. ${ }^{61}$ With respect to the use of oligonucleotide-based miRNA therapeutics, challenges like poor cellular uptake or a low bioavailability need to be further addressed, as well as off-target effects or long-term safety in humans. A means to target such problems is the combination of miRNA-based therapeutic technologies with other forefront technologies, including nanoparticles or polymers. For sure, miRNA-based approaches bear a great potential for novel therapeutics, genome and personalized medicine.

\section{References}

1. Lee Y, Kim M, Han J, et al. MicroRNA genes are transcribed by RNA polymerase II. EMBO J 2004;23:4051-60.

2. Gregory RI, Yan KP, Amuthan G, et al. The microprocessor complex mediates the genesis of microRNAs. Nature 2004;432:235-40.

3. Lund E, Guttinger S, Calado A, et al. Nuclear export of microRNA precursors. Science 2004;303:95-98.

4. Chendrimada TP, Gregory RI, Kumaraswamy E, et al. TRBP recruits the Dicer complex to Ago2 for microRNA processing and gene silencing, Nature 2005; 436:740-4.

5. Alvarez-Garcia I,Miska EA MicroRNA functions in animal development and human disease. Development 2005;132:4653-62.

6. Pang KC, Stephan S, Dinger ME, et al. RNA2b 2.0 - an expanded database of mammalian non-coding RNAs. Nucleic Acids Res 2007;35:D178-82.

7. Bartel DP. MicroRNAs: genomics, biogenesis, mechanism, and function. Cell 2004; 116:281-97.

8. Iorio MV, Ferracin M, Liu CG, et al. MicroRNA gene expression deregulation in human breast cancer. Cancer Res 2005; 65:7065-70.

9. Michael MZ, O'Connor SM, van Holst Pellekaan NG, et al. Reduced accumulation of specific microRNAs in colorectal neoplasia. Mol Cancer Res 2003;1:882-91.

10. Takamizawa J, Konishi H, Yanagiswaw K, et al. Reduced expression of the let-7 microRNAs in human lung cancers in association with shortened postoperative survival. Cancer Res 64:3753-6.
11. Esquela-Kerscher A, Slack FJ. Oncomirs microRNAs with a role in cancer. Nat Rev Cancer 2006;6:259-69.

12. Calin GA, Dumitru CD, Shimizu M et al. Frequent deletions and down-regulation of micro-RNA genes miR15 and miR16 at $13 q 14$ in chronic lymphocytic leukemia. Proc Natl Acad Sci USA 2002;99:15524-9.

13. Cimmino A, Calin GA, Fabbri M et al. MiR15 and miR-16 induce apoptosis by targeting BCL2. Proc Natl Acad Sci USA 2005;102:1394409.

14. Calin GA, Sevignani C, Dumitru CD, et al. Human microRNA genes are frequently located at fragile sites and genomic regions involved in cancers. Proc Natl Acad Sci USA 2004;101:2999-3004.

15. Volinia S, Calin GA, Liu CG, et al. A microRNA expression signature of human solid tumors defines cancer gene targets. Proc Natl Acad Sci USA 2006;103:2257-61.

16. Scott GK, Goga A, Bhaumik D, et al. Coordinate suppression of ERBB2 and ERBB3 by enforced expression of microRNA miR-125a or miR-125b. J Biol Chem 2007;282:1479-86.

17. Rossbach M. Small non-coding RNAs as novel therapeutics. Current Molecular Medicine 2010;4: 361-368.

18. Ma L, Teruya-Feldstein J, Weinberg RA. Tumor invasion and metastasis intiated by microRNA-10b in breast cancer. Nature 2007;449:682-8.

19. Ma L, Reinhardt F, Pan E, et al. Therapeutic silencing of miR-10b inhibits metastasis in a mouse mammary tumor model. Nat Biotechnol. 2010;28:341-7.

20. Lu J, Getz G, Miska EA, et al. MicroRNA expression profiles classify human cancers. Nature 2005;435:834-8.

21. Yanaihara N, Caplen N, Bowman E, et al. Unique microRNA molecular profiles in lung cancer disagnosis and prognosis. Cancer Cell 2006;9:189-98.

22. Shi M, Guo N. MicroRNA expression and its implications for the diagnosis and therapeutic strategies of breast cancer. Cancer Treat Rev 2009;35:328-34.

23. Lynam-Lennon N, Maher SG, Reynolds JV. The roles of microRNA in cancer and apoptosis. Biol. Rev. Camb. Philos. Soc. 2009; 84:55-71.

24. Zheng T, Wang J, Chen X, Liu L. Role of microRNA in anticancer drug resistance. Int. J. Cancer 2010;126:2-10.

25. Ota A, Tagawa H, Karnan S, et al. Identification and characterization of a novel gene, C13orf25, as a target for 13q31-q32 amplification in malignant lymphoma. Cancer Res 2004;64:3087-95.

26. Mendell JT. MiRiad roles for the miR-17-92 cluster in development and disease. Cell 2008;133:217-22.

27. Johnson SM, Grosshans H, Shingara J, et al. RAS is regulated by the let-7 microRNA family. Cell 2005;120:635-47.

28. Lee YS, Dutta A. The tumor suppressor microRNA let-7 represses the HMGA2 oncogene. Genes Dev 2007;21:1025-30.

29. O'Donnell KA, Wentzel EA, Zeller KI, et al. CMyc- regulated microRNAs modulate E2F1 expression. Nature 2005;435:839-43.

30. Johnson CD, Esquela-Kerscher A, Stefani $\mathrm{G}$, et al. The let-7 microRNA represses cell proliferation pathways in human cells. Cancer Res 2007:67;7713-22.

31. Mirnezami AH, Pickard K, Zhang L, et al. MicroRNAs: key players in carcinogenesis and novel therapeutic targets. Eur J Surg Oncol 2009;35:339-47.

32. Du Y, Xu Y, Ding L, et al. Down-regulation of miR-141 in gastric cancer and its involvement in cell growth. J Gastroenterol 2009;44:556-61.

33. Zhang Z, Li Z, Gao C, et al. MiR-21 plays a pivotal role in gastric cancer pathogenesis and progression. Lab Invest 2008;88:135866.

34. Kim YK, Yu J, Han TS, et al. Functional links between clustered microRNAs: suppression of cell-cycle inhibitors by microRNA clusters in gastric cancer. Nucleic Acids Res 2009;37:1672-81.

35. Petrocca F, Visone R, Onelli MR, et al. E2F1-regulated microRNAs impair TGFbetadependent cell-cycle arrest and apoptosis in gastric cancer. Cancer Cell 2008;13:272-86.

36. Rodriguez A, Griffiths-Jones S, Ashurst JL, Bradley A. Identification of mammalian microRNA host genes and transcription units. Genome Res. 2004;14:1902-10.

37. Kim MS, Oh JE, Kim YR, et al. Somatic mutations and losses of expression of microRNA regulationrelated genes AG02 and TNRC6A in gastric and colorectal cancers. J Pathol 2010;221:139-46.

38. Calin GA, Croce CM. Chromosomal rearrangements and microRNAs: a new cancer link with clinical implications. J Clin Invest 2007;117:2059-66.

39. Saito Y, Suzuki H, Tsugawa H, et al. Chromatin remodeling at Alu repeats by epigenetic treatment activates silenced microRNA-512-5p with downregulation of Mcl-1 in human gastric cancer cells. Oncogene 2009;28:2738-244.

40. Ueda T, Volinia S, Okumura $\mathrm{H}$, et al. Relation between microRNA expression and progression and prognosis of gastric cancer: a microRNA expression analysis. Lancet Oncol 2010;11:136-46.

41. Li X, Zhang Y, Zhang Y, et al. Survival prediction of gastric cancer by a sevenmicroRNA signature. Gut 2010;59:579-85.

42. Mitchell PS, Parkin RK, Kroh EM, et al. Circulating microRNAs as stable bloodbased markers for cancer detection. Proc 
Natl Acad Sci USA 2008;105;10513-8.

43. Chen X, Ba Y, Ma L, et al. Characterization of microRNAs in serum: a novel class of biomarkers for diagnosis of cancer and other diseases. Cell Res 2008;18:997-1006.

44. Tsujiura M, Ichikawa D, Komatsu S, et al. Circulating microRNAs in plasma of patients with gastric cancers. Br J Cancer 2010;102:1174-9.

45. Valadi H, Ekström K, Bossios A, et al. Exosome-mediated transfer of mRNAs and microRNAs is a novel mechanism of genetic exchange between cells. Nat Cell Biol 2007;9:654-9.

46. Kota J, Chivukula RR, O'Donnell KA, et al. Therapeutic microRNA delivery suppresses tumorigenesis in a murine liver cancer model. Cell 2009;137:1005-17.

47. Rossi JJ. New hope for a microRNA therapy for liver cancer. Cell 2009;137:990-2.

48. Chang TC, Yu D, Lee YS, et al. Widespread microRNA repression by Myc contributes to tumorigenesis. Nat Genet 2008;40:4350.

49. Weiler J, Hunziker J, Hall J. Anti-miRNA oligonucleotides (AMOs): ammunition to target miRNAs implicated in human disease? Gene Ther 2006;13:496-502.

50. Jiang Z, Guo J, Xiao B, et al. Increased expression of miR-421 in human gastric carcinoma and its clinical association. $\mathrm{J}$ Gastroenterol 2010;45:17-23.

51. Cho WJ, Shin JM, Kim JS, et al. MiR-372 regulates cell cycle and apoptosis of ags human gastric cancer cell line through direct regulation of LATS2. Mol Cells 2009;28:521-7.

52. Ji Q, Hao X, Meng Y, et al. Restoration of tumor suppressor miR-34 inhibits human p53-mutant gastric cancer tumorspheres. BMC Cancer 2008;8:266.

53. Tarasov V, Jung P, Verdoodt B, et al. Differential regulation of microRNAs by p53 revealed by massively parallel sequencing: miR-34a is a p53 target that induces apoptosis and G1-arrest. Cell Cycle 2007;6:1586-93.

54. Xia L, Zhang D, Du R, et al. MiR-15b and miR-16 modulate multidrug resistance by targeting BCL2 in human gastric cancer cells. Int J Cancer 2008;123:372-9.

55. Aagaard L, Rossi JJ. RNAi therapeutics: principles, prospects and challenges. Adv Drug Deliv Rev 2007;59:75-86.

56. Zhao X. Controlled delivery of antisense oligonucleotides: a brief review of current strategies. Exp Opin Drug Deliv 2009;6: 673-86.

57. Malik R, Roy L. Design and development of antisense drugs. Exp Opin Drug Discov 2008;3:1189-207.

58. Chiarantini L. Comparison of a novel delivery systems for antisense peptide nucleic acids. J Control Release 2005;109:24-36.

59. Zuhorn IS, Engberts JB, Hoeckstra D. Gene delivery by cationic lipid vectors: overcoming cellular barriers. Eur Biophys J 2007; 36:349-62.

60. Chirila, TV. The use of synthethic polymers for delivery of therapeutic antisense oligodeoxynucleotides. Biomaterials 2002; 23:321-42.

61. Kotani A, Ha D, Hsieh J, et al. MiR-128b is a potent glucocorticoid sensitizer in MLLAF4 acute lymphocytic leukemia cells and exerts cooperative effects with miR-221. Blood 2009;114:4169-78. 